Canadian Journal of Family and Youth, 5(1), 2013, pp 107-149

ISSN 1718-9748 @ University of Alberta

http://ejournals.library.ualberta.ca/index/php/cjfy

\title{
Challenges of the Visible Minority Families: Cultural Sensitivity to the Rescue
}

\author{
Adenike Yesufu
}

\begin{abstract}
This paper not only attempts to outline in one location the many barriers faced by visible minority families in their attempt to integrate into Canadian Society, but it also seeks to offer the development of a new approach to the solution of the problem of Cultural Sensitivity. On the premise that education is transformational, programs like Global education, Multicultural Education, Intercultural Education, Antiracist Education, and Diversity Education have been instituted in Canadian schools. Unfortunately these programs have had serious problems and have been severely criticized in their implementation even by their supporters. They all have different focuses and agendas that do not strike at the core of the problems nascent to majority/minority dynamics in Canada. The ultimate goal of these programs, presumed to be able to attain cross-cultural competence, has left many wondering how effective these programs have been. McChesney (1996) wondered if there was hope for cultural studies. The problems of the visible minority immigrant families have seemed persistent. The frustrations of the younger generation of visible minority families continue to be bewildering. This writer feels it is time to change course.
\end{abstract}

\section{Visible Minority Families: Settlement and Integration Issues}

Albaneze (2009) described Canada as a land of immigrants that has, over the years, become home to millions of refugees and immigrants from around the world. Canada's immigrant populations have included white immigrants from Europe, black people from Africa and the Caribbean, brown people from Asia Middle and the Far

Dr. Adenike Yesufu's doctorate degree is in International/Intercultural Education from the University of Alberta. In addition to being a Sociology Instructor at Grant MacEwan University she is extensively involved in Diversity and Cross Cultural issues. She is a Certified Canadian Counselor (CCC) with a special focus on families. She is committed to promoting women's interests in various areas. 
Yesufu

East. My essay is a specific focus on the group that has been designated "the visible minority." Most of the members of this group usually arrive in Canada as families partly because they have come from communalistic societies where group belongingness is vital and also because for them, families are not only the framework for survival but also a social life that prepares new members to participate in the social, spiritual and economic aspects of their society.

The Immigration Regulations of 1967 introduced a new immigration system to Canada. Changes to the Immigration Act removed race restrictions for entry to Canada and introduced the new merit point system which is still in practice. Independent individuals and families were granted entry to Canada based on the number of points accorded for various qualifications they possess, education, job skills, knowledge of English or French and so on but not the color of their skin or their country of origin (Albanese, 2009). Added to these have been international students, temporary skilled workers, domestic workers, economic/business immigrants, the refugee group, and the family reunion class. As a result of these, there has been a significant increase in the number of visible minority immigrants in Canada (Frideres, 2007).

In March 1984, the term "visible minority" was sanctioned by the Canadian government as the appropriate label for all "non white" people in Canada. Included in this definition are Aboriginal people, and those with origins in Africa, China, India, Pakistan, Japan, Korea, Southeast Asia, Latin America, the Pacific Islands, the Philippines and the Arabic countries. Thus was born Canada's official label for all nonwhite immigrants. By 2001, about $14 \%$ of people living in Canada were considered to 
be visible minorities (Albanese, 2009). Statistics Canada (2005) projected that $23 \%$ of the nation's population could be a member of a visible minority by 2017 .

The label "visible minorities" have continued to pose some problems for the people in this category regardless of where they come from. It affects virtually all aspects of their lives, socioeconomic, political, religious, and educational. Many have to deal with the consequences of this label as well as the distortions it creates in their identity formation. Simms (1990) challenged the term and wondered if the problem that both government and private sectors have in implementing employment equity programs lies partially in the use of the label "visible minority". She also thinks that this label obscures the real problem of injustice and racism in Canadian society. She adds that the targeting and labeling of one group results in inequity and possibly creates a "hierarchy of the oppressed". It is therefore more important for Canada to focus on the solution to Canada's minority problems than ascribing an exotic label to the one out of every four Canadians who fall into this category. James (2011) on the "visible minority" category posits that the term tends to conceal the failures or at least, the limits of 'equitable' hiring initiatives for some racial groups while simultaneously showing success for others.

In October 1971, multiculturalism was declared an official policy of Canada. The Multicultural Policy of Canada was designed to enhance settlement and integration of immigrants into Canada. The emphasis was also on celebrating differences and the removal of some of the systemic barriers which would facilitate the integration of visible minorities into Canadian society. Hate propaganda against identifiable groups became a criminal offense in 1970. In 1966, Canada ratified the International 
Yesufu

Convention of the Elimination of all forms of racial discrimination which had been adopted by the United Nations in 1965 . The Canadian government began to give more attention to equality issues. The Canadian Human Rights Act of 1977 and various provincial human rights code were also enacted to provide greater protection of minority rights (Hutter, 2004). The Government of Canada through Immigrant and Multicultural services and agencies has been providing services and programs to support individuals and families to adjust to life in Canada. The government also began to support heritage languages and ethno-cultural activities by communities to enhance their long term integration. Programs were designed to promote social change in areas relating to multiculturalism, human rights and antiracism (Christensen, 2001). The Settlement services and Multicultural societies have been making some attempts at delivering public education programs to serve the interest of these visible minority immigrant individuals, families and communities.

For the past thirty years, Canada has steadily been bringing in about 250,000 immigrants each year (Immigration Canada Watch, 2012). Canada's population has just reached the 35 million mark. This essentially translates to a continued increase in Canada's diversity. For the immigrants, the motives for immigration continue to be the yearning for a better life. Whenever immigrants have arrived in Canada it meant that they have been uprooted from their old environment and have to face the necessity of coming to terms with an unfamiliar environment and a new status (Hutter, 2004). Since the inception of the Multicultural Policy, the Canadian government has put in place structures that should have ensured the successful integration and satisfying settlement of all immigrants. Unfortunately, study after study has shown that visible minority 
Visible Minority Families

immigrant individuals and families in Canada have continued to encounter serious challenges in settling down and integrating in Canada. The ultimate success of any immigrant group is to reestablish a normal pattern of family life in their new location. This has proven difficult for many visible minority immigrants' individuals and families in Canadian society. Smith (2011) says "as we welcome 2011, we must acknowledge that in an ever more diverse Canada, inequities persist and must be confronted with renewed determination" (Equity Matters FEDCAN BLOG). She also cited then Judge Rosalie Silberman Abella who in 1984 said that "the systemic barriers and obstacles faced by women and minorities, are so formidable and self-perpetuating that they cannot be overcome without intervention. It is both intolerable and insensitive if we simply wait and hope that the barriers will disappear over time" (Royal Commission Report on Equality in Employment, 1984).

The term settlement as employed by the Canadian government means that new immigrants and new comers have the wherewithal to survive in their new home. It includes their having access to appropriate housing and some other supplemental needs necessary for integration into the various communities located all across Canadian cities (Edmonton Mennonite Centre, 2010). While all immigrants including those of the dominant racial group may have settlement problems arising from relocation, the integration issues usually apply to visible minority immigrants because they have to deal with problems that set them apart from other immigrants. To start with, some of the visible minority immigrant individuals and families may have very limited proficiency in English, meaning that they have to learn a new language or improve on the level that they have, even though they may have been highly educated in their country of origin. 
Yesufu

These visible minority immigrants have to spend years learning English. The process takes so long that they always never seem to catch up, they are not able to attain the level of proficiency needed to operate effectively in society, nor are they able to acquire the level of advanced education that they would like. The result is that upward mobility remains a challenge for them and this eventually affects their desired improved status in their new society. These families soon become disgruntled and disillusioned because of their struggle with upward mobility and so begins their journey of disenchantment with their new country (Fleras, 2005).

While looking for work, most visible minority immigrants have to deal with the peculiarities of the job market because the job dynamics in Canada may differ significantly from those of their country of origin. Most have to go through a process of understanding and adjusting to the various social institutions and systems in Canada, like the many government agencies, educational systems, medical services, and laws that are usually unlike what they are used to (Frideres, 2007). Another impediment to settlement and integration is that visible minority immigrants themselves develop strong attachments to their community, a strong ethnic identity and involvement in their communities which in effect keep them minimally or maximally detached from the rest of society. The result has both positive and negative effects on social integration. For example, a positive effect would be support from the community while a negative effect would be their postponed integration into mainstream culture, which may result in alienation. With the negative effects at times outweighing the positive, visible minority immigrants and their families begin to struggle (Reitz, 2007). 
Visible Minority Families

\section{Challenges of Visible Minority Families Rooted in Systemic Discrimination and Racism}

Abella (1984) defines systemic discrimination as the institutionalized system and practices that result in arbitrary and extensive exclusion of persons who by reason of their group affiliation are systematically denied a full opportunity to demonstrate their individual abilities. Clark (1993) says that racial discrimination like all forms of cruelty and tyranny, debases all human beings, those who are its victims, those who victimize and in subtle ways, those who are its accessories. Fleras (2005) says that from afar, Canada looks like a paragon of racial tranquility, because laws have been put in place that not only prohibit racism and discrimination but also punish those who flout Canada's multicultural ideals. Nonetheless, he says racism is alive and well in Canada and its worst effects are camouflaged by a veneer of politeness, denial and good luck. Satzewich (2000) says that the image of Canada and Canadians as tolerant is entirely not accurate as the reception that visible minority immigrants and refugee groups have received following their arrival have tended to somewhat fall short of ideal. He adds that while racism and discrimination are arguably not as prevalent in Canada as in some other countries, they do constitute an important part of the social, political and economic structures that exist and that while some of its pernicious aspects are rejected by many Canadians, the "non white" groups continue to be seen as "other".

The Multiculturalism Policy involves supporting visible minority communities, promoting intergroup and interpersonal harmony, providing resources for integration, and equal access to full participation in Canadian society (Hiller, 2005). Christensen (2001) says that it also promotes cultural and racial diversity as a fundamental characteristic of Canadian heritage identity, equitable participation of individuals and 
communities of all origins in Canadian society, removal of barriers to participation and access to services and equal treatment and protection under the law. Ujimoto (2000) states that multiculturalism as a state policy seeks to legitimize the values, norms, beliefs and identity of all ethnic groups, yet visible minorities in Canada continue to experience significant inequality and often report instances of discrimination. He adds that against the expectations of visible minority groups, concerns about inequality grow, intensify and deepen with greater time in Canada. Olson, DeFrain and Skogrand (2008) states that the initial positive outlook of Canada soon fades as visible minorities begin to experience systemic discrimination. Reitz (2007) indicates that, unfortunately, many Canadians simply discount reports of discrimination as unimportant while 34 percent of visible minorities continue to report experiences of discrimination. They often report discomfort in social situations, and also express fear of becoming the target of an attack. Reitz (2007) concludes that equity policies that are designed to promote the idea of racial equality and curtail this trend have obviously been insufficient, meaning that the impact of the policies has been negligible and the expected positive effects have been dismal.

Statistics Canada's landmark Ethnic Diversity Survey (2008) showed that 35 percent of visible minorities had reported personal experiences of discrimination within the previous five years, and most of these were in the workplace. Within minority groups, the perceptions of the existence of racial discrimination in employment are widespread (Canadian Social Development Council, 2000). Hou and Balakrishnan, (2004) in their studies of the situation have indicated that partly as a result of experiences of discrimination, visible minority immigrants are slower to socially 
integrate into Canadian society than their white immigrant counterparts. Kobayashi (2010) claims that people of color are subject to stereotypes and denigration. They are made invisible, as though their experiences do not matter and as though the principle of equality means that differences created by racism have no meaning at all.

Kobayashi (2010) adds that racism and discrimination against visible minority takes many forms, ranging from overt racism which may take the form of a public statement about the inferiority of members that have been racialized, to polite racism which attempts to disguise a dislike of immigrants, to institutionalized and systemic racism which is made up of rules, procedures and practices that directly and deliberately prevent minorities from having full and equal involvement in society while reinforcing white experiences as normal and that of minorities as inferior or irrelevant. The act of excluding visible minority groups continues to have harmful impacts on them.

Immigration Watch Canada (2011) expressed the view that Canada's 250,000 per year immigration intake since 1990 has been far too high and that this has had major negative economic consequences for Canadians who are looking for work. It adds that immigration has been turned into a social assistance/job-finding program for people from other countries. It also says that immigration has forced many of Canada's own unemployed to compete with immigrants for a limited number of jobs and that it has impoverished many Canadians. This is clear evidence of the resentment that visible minority immigrants have to contend with. They have been made scapegoats, by those who are frustrated because they have not been able to achieve their desired goal. These people have turned their aggression on to minorities who themselves are frustrated and are not capable of offering resistance to the hostility and aggression being directed at 
Yesufu

them. Alboim and Cohl (2112) in their report on the study that examined changes made to the immigration and refugee systems by the Conservative government between 2008 and 2012, say that the unpredictable changes made to the Immigration and Refugee policies painted immigrants as "cheaters and fraudsters" and make Canada less welcoming (MAYTREE Foundation Report, 2012). In addition to all these issues, Kobayashi (2010) says the experiences of discrimination and racism by visible minority immigrants and their families continues to be under-reported resulting in a classic denial of its existence by some mainstream members of the population.

To start with, for many families, work is the means to secure a future. The ultimate success of any immigrant family depends largely on their ability to re-establish a normal pattern of family life in Canada. This often means the ability to have jobs and the economic independence to meet family needs (Doucet, 2007). At times, this proves difficult for visible minority immigrants families. Reitz (2007) says that one major problem that continues to confront the visible minority immigrant individuals and their families is the inability to get jobs quickly once they arrive in Canada and that they face the perennially difficult challenge of finding employment. This is particularly true for those arriving without prearranged employment. The immediate demands of settlement issues at times distracts from the needed focus on employment searches. Furthermore, new immigrants are required to learn new workplace practices which may be timeconsuming and diversionary. Knowledge of the labour market is also limited for many visible minority immigrants and this contributes to their delay in securing jobs. Creese, Dyck, and Mclaren (2009) identified the most significant problem faced by visible minority individuals and families as the unexpected non-recognition of their certificates 
from their homeland and the notorious demand for "Canadian experience" by employers. This is often the first shock they experience because admissibility to Canada is based on the skills, educational qualification and experiences that immigrants possess. Obtaining a visa to Canada presumes that immigrants' qualifications will be recognized by employers in Canada presenting the opportunity to accumulate the much touted Canadian work experience. It usually does not happen this way. Unfortunately, foreign job experience has little value in the Canadian labour market. There is an established irreverence of occupational or professional experience gained abroad. This unusual discriminatory practice often results in delay or the inability to secure jobs in Canada. Hence, visible minorities have to go through the process of resocialization by acquiring what is usually described as more relevant types of education. This could take years resulting in severe frustration.

At times, some visible minority immigrants do not speak English so they have to enroll in ESL (English as a Second Language) programs, where it may take many years to attain the needed language proficiency. With the non-recognition of previous certification, some have to take jobs at the lower level of strata, which usually increases the challenges that they face in the search for integration and upward mobility. The question then arises as to what is the validity and usefulness of the lengthy and tedious screening and processing of immigrants' qualification and skills before being deemed qualified to come to Canada? Frideres (2007) says that this situation raises false hope. The non-recognition of previous experiences becomes very shattering for the visible minority immigrant groups and sets them back years in their quest for upward mobility. Many have indicated that anxiety about work, educational and occupational 
Yesufu

opportunities led them to worry about how to support their families. This specific problem in work situation places them in the lowest household incomes as most times they have to resort to "survival" jobs for which they are over-qualified or are not in any way related to the experiences that they have accumulated before coming to Canada. The socioeconomic status of new visible minority immigrants created by unemployment or underemployment naturally has an impact on the functioning of their families. Frideres (2007) however, notes that the economic status of some visible minority immigrants does improve with time in Canada as they eventually overcome the initial work related problems that threaten to derail their aspirations and goals because those who have jobs and a reasonable incomes are able to obtain adequate housing, provide social amenities for family members, achieve higher educational goals and are likely to command supervisory and managerial authority.

Integration is another issue for visible minority immigrant families. Beiser et.al. (2002) defines the various patterns of integration of visible minority immigrant families. On arrival in Canada, they can try to preserve the culture of their origin, they can try to become Canadian as quickly as possible, or they can try to develop a hybrid pattern that incorporates both the old and the new. Regardless of the strategy that they choose, visible minority immigrant families always struggle to find ways to cope with the new norms, values and behaviors of Canadian society. Their living patterns always contribute to their effective or non-effective settlement and integration into their new home.

Visible minority immigrant families are less likely to live in lone parent households rather, some opt for the joint family arrangement which is a type of 
Visible Minority Families

extended family composed of parents, their children, and the children's spouses and offspring in one household. This arrangement has advantages and disadvantages. Visible minority immigrant families tend to have more children, hence there is collaboration and cohesiveness among family members and a ready support for each other and for children which can result in good academic performance and overall psychological well-being (Beiser et.al., 2002). However Jha (2001) disclosed the disadvantage of this living arrangement - overcrowded accommodation and some other difficulties which are not always addressed by the settlement and integration agencies. He says that sometimes the interests and well-being of the younger members can suffer because of undue importance given to upholding the ideals of joint family. The young members may reject joint parenting in an individualistic culture like Canada. This system at times also breeds contempt among the members who earn less than the ones who earn more and whose monetary contribution is maximum towards the family. Family feuds regarding family property may ensue. All issues if not addressed may lead to the eventual break-up of the family defeating the goal of family integration.

Another issue for visible minority groups is marriage patterns. In many countries throughout the world marriage is seen as an arrangement between two families. An alliance through marriage between two families can enhance the power, prestige and well-being of the family members, therefore one marries not just an individual but also the person's family. Visible minority groups usually favour endogamous marriages. They marry persons of the same or similar ethnic or cultural group because of the advantages of similarity. Frideres (2007) however observes that this is changing especially since the 1960s when the number of intermarriages has increased. Today, 
Yesufu

over $30 \%$ of all unions in Canada involve visible minority and non-visible groups.

Cross-cultural marriages have continued to increase. Canada's overall intermarriage rate is the highest in the world. Social and geographic mobility of people means more opportunity to meet people of different backgrounds. Canada's increasing diversity has continued to provide greater opportunities to meet in educational settings, in the workplace and in other social environments. With increasing immigrant populations in Canada, residents have a larger pool to draw from for potential marriages partners.

Traditionally, endogamous marriage viewed intercultural marriage as more difficult, unstable and more conflictual than marriage within one's own culture. Jedwab (2004) however, observes that despite Canada's increasingly heterogeneous society, many mainstream Canadians do not feel comfortable with their children marrying someone from other groups and do not hesitate to state their opinion. Some visible minority immigrant populations also demonstrate some resentment towards this trend. The result is that visible minority immigrant families who have chosen to engage in cross-cultural relationships and marriages have problems of acceptance within their own specific families and communities. These problems are manifested as rejection, discrimination, disapproval by friends and members of their communities, and even family conflicts and violence which have caused instability within the union and which have in turn made assimilation and acculturation difficult.

Within the marriage system, Frederes (2007) identifies another challenge facing visible minority immigrant parents; their children opting for common law arrangements in intercultural relationships. As much as common law or cohabitational relationships are on the increase in Canada, many visible minority immigrant families still find it 
unacceptable and counter to their culture. These relationships also lack social acceptance in some religious circles. Visible minority immigrant parents are shocked to find their children choosing this practice and blame it on the prevailing permissive culture that allows and favors this practice. This puts them on a course of conflict with the system. Frederes (2007) however, notes that on the other hand, some immigrant families are increasingly demonstrating their acceptance of Canada's diversity and are becoming more open to the inevitable consequences of marriage and intercultural intimate relationships with people from other communities. The hope is that as time goes by Canadian minorities and mainstream families will all become more accepting of exogamous marriages and intercultural relationships.

Every culture has images and ideas about how children should be socialized. While the visible minority adults are struggling with settlement and integration issues, they have been known to complain about the struggles that their children are also experiencing. They watch their children struggle to become integrated with their peers, they watch them experience rejection by some members of society and they watch them come home broken-hearted from school because their peers have called them names. They see their children become gradually transformed into resentment-filled people because of society's reaction and treatment towards them and then they wonder why they had migrated at all. Rer-Strier (1996) identified three strategies employed by visible minority immigrant parents when faced with these problems. The first one is unicultural which involves parents remaining as the primary socializing agents. The second one is rapid assimilation where parents withdraw as the chief socializing agent and defer to other agents in the new country (for example, teachers and social service 
Yesufu

professionals) who assume responsibility for raising their children. The third is bicultural which involves encouraging the child to live in a bicultural world. In the home for family related activities, the parents are the chief socializing agents but outside the home the children are expected to conform to the culture of their new environment. Rer-Strier (1996) adds that all these patterns have their risks as does Brandon (1996). In fact, Brandon (1996) observed that retaining one's own culture in the unicultural strategy results in lack of integration and reduces social and economic opportunities. Albanese (2009) observed that when visible minority immigrant parents come to Canada they are faced with different and sometimes conflicting ideas on parenting. These parents usually have high educational aspirations for their children and so engage in authoritarian parenting which often results in conflict within the family. Mykovicj (2000) suggests that most visible minority parents struggle with parenting during the earlier stage of migration. The younger generation strives to create a relatively independent life while the older generation tries to maintain control of the children. Olson, DeFrain \& Skogrand (2008) report that some teens feel isolated on arrival in Canada. However, younger children adjust very quickly as the second generation integrate more easily than the first. The young members want to be accepted by the mainstream and at the same time, they want to maintain a connection to their families. Clash of cultures and changing roles in families remain problematic for them (Mykovicj, 2000). Visible immigrant children who arrive without sufficient English acquire it much more rapidly than do their parents and may act as actual brokers and translators and interpreters for their parents as they come to an understanding of the 
culture and experience integration much earlier than their parents and become aware of Canadian expectations earlier than their parents.

Parents also transmit their cultural perspectives to their children including their religious practices. Visible minority immigrant families in Canada, at times, also have to struggle with their religious and spiritual values. Many of them have come from religious societies. Canada is usually deemed to be a more secular society. Religious parents have to be far more vigilant and invest far more effort in insulating their children against the general secular climate. Even the popular culture in Canada is at times different from their taste, values and experiences. When families arrive in Canada they see that they need to have the full mastery of how social institutions function, so they can be to be fully integrated into the society. They are not always successful because there are too many social pressures working against them (Ambert, 2012). Visible minority immigrant parents, to their chagrin, see their children struggling to fit into the new culture while inevitably losing touch with their home traditions.

Family and school compatibility may also be difficult for visible minority children because there are at times no synchronicity between the culture at home and that of the school (Olson, DeFrain \& Skogrand, 2008). At times, visible minority parents may not be in a position to become involved with the school system or to help their children with homework even when they are highly educated because they themselves may be struggling to make ends meet and so are unable to be supportive as they might have been in their country of origin.

Clark (2007) while discussing the position and adjustment of the visible minority immigrant youth in Canada debunked the previously held view that they are 
Yesufu

quite resilient and always become similar to Canadian-born children quite quickly. He identified two possible outcomes for visible minority immigrant children. The first was described as assimilation with economic success. In this instance, the visible minority immigrant youth usually turn out to be more educated than their parents (even up to three or four generations). They are less likely to drop out of school and so eventually have higher educational achievements, experience fewer periods of unemployment, and receive higher earnings. The second scenario is that visible minority immigrant youth assume an underclass identity and integrate into marginal labour markets. The youth in this category are not as lucky as the first group and so are impoverished and are more likely to leave home and school earlier than their other counterparts and may experience disadvantages in the labour force. Statistics Canada (2001) in a study of visible minority immigrant youth affirms that youth unemployment and poverty result in delayed transition to adulthood, postponement of marriage and a life of independence as adults.

Also, many visible minority immigrant families have established businesses in Canada and they expect and want their children to be involved so that they can take over the business in their adult years. In short, they expect them to participate fully. However, young people from all ethnic groups engage in similar activities of watching television, listening to music, spending time with their friends and generally participating in the prevalent youth culture. Children of visible minority immigrants born in Canada want acceptance from their peers and so they rely, listen to, and spend more time with their peers, savoring the new taste of freedom and wanting to spend more time on social activities and less on academic pursuits and less time devoted to 
interaction or working with their parents. This type of scenario usually translates into conflicts and struggles within the family unit.

In terms of gender dynamics among visible minorities, Boyd and Vickers (2004) observe that men greatly outnumber women among people settling in Canada because labor recruitment often targets men rather than women. This has caused an imbalance gender ratio among visible minority immigrants in Canada. With respect to migration flow, particularly those motivated by economic reasons, men frequently precede women because the move is viewed as temporary and because the men intend to become economically established before being joined by his family. But of course, women also migrate for economic reasons, and given the strong demand for female domestic workers, many women were granted immigration status to Canada. The role of women in the family in all cultures is an important issue that has short and long term consequences for all involved. However, men and women are treated differently as they settled in Canada.

While women of all kinds enter Canada through its multiple immigration streams, women still tended to be largely associated with immigration via the "family class" category. In recent times, the Canadian government has been downgrading family class immigration, and promoting the "economic" routes that have grown in scope and number (Dobrowolsky, 2010). There are now several new programs and initiatives aimed at upping the entry of highly skilled, well-educated and wealthy migrants at both federal and provincial levels. More men are found in these preferred immigration categories, because men, in general, have greater financial capital and "human" capital in terms of much sought after skills and educational levels. Since larger numbers of 
Yesufu

women still enter through the family class, fewer women come as principal applicants (Dobrowolsky, 2010).

Man (2009) suggests that minority immigrant women's independence and control over their lives may become limited with the patterns of living in Canada. On arrival in Canada, visible minority immigrant women find that they have to do a lot of things by themselves, because the support they are used to in their communalistic society has been lost. They discover that it is more difficult to care for the family, raise children, and pursue other activities in an individualistic culture like Canada. They find it stressful that they cannot leave their children in the care of others like family members as they would back home because here everyone is occupied with their own families. They find it strange that they cannot leave their younger children in the care of their older siblings (who may also still be young) as they would back home or else they would be accused of parentifying their children (Brenizer, 2008). Caring for children therefore becomes more time consuming. At times, visible minority immigrant women also have to look after their newly arrived relatives to help them settle. They, at times, find all these situations exhausting. They feel constrained and resent the dependence of family members while they too are still struggling for survival.

In April, 1992 the Ministry of Employment introduced the Live In Care Giver Program. According to this policy, women intending to do domestic work would be admitted to Canada on the basis of their education and training and the experiences that they have related to the care of children, seniors and the disabled. This domestic service program was put in place by Canada to help mainstream families who need the support and can afford it. Unfortunately, this policy has created a class of highly racialized 
individuals among the group of visible minority immigrant women. This aspect of work, housework and childcare is a highly gendered occupation, which has also produced women who are vulnerable. The women constitute a cheaper source of labor because employers are compelled to only pay minimum wage. This does not do much for the emancipation of women (Bakan and Stasiulis, 1994).

One of the problems for these women is that they are only granted a temporary stay. Although this group of women can apply to become landed immigrants, it usually takes up to five years for them to get their families to Canada. Many people consider this strange considering the fact that Canada continuously touts itself as a country that believes in the unification of families. Some of these women usually have children whom they have left behind to come over to work in Canada. This creates a lot of stress as the separation is very painful for them. Even though immigrant domestic workers are able to remit money to the families back home, the women have to deal with profound guilt and loneliness (Sesdef Arac-Koc, 2009). The problems however, do not end when the children eventually join their parents in Canada. Some are resentful of their parents who have left them behind, although some are understanding and assume that their mothers did it out of love for them. Most women find it difficult to help the children get over the feeling of abandonment they have been experiencing when they arrive in Canada. They find it difficult to undo the distance; the gulf that has been created between them and their children. This creates more problems in parenting for the female headed visible minority immigrant families (Arac-Koc and Villaisin, 2001).

Sesdef Arac-Koc (2009) identifies another problem experienced by female visible minority immigrants. These women usually describe their rationale for coming 
Yesufu

to Canada as being rooted in the notions of safety, security and well-being for their children. However, many of them (because of a lack of Canadian experience) will take what has become known as "survival" jobs to provide immediately for their families. Even though many of them are over-qualified for the jobs that they do, they are also compelled to do multiple jobs to survive. This places a lot of stress on their children because they are not always around to look after them. Soon the relationship with their children becomes strained and the children resent the fact that their mothers are not around all of the time. When such children begin to experience difficulties as they are likely to, they blame the parent who brought them to Canada. Frideres (2007) talks of astronaut families, where as soon as the reality of unemployment or underemployment sets in, the heads of household, usually the husbands, when they cannot get suitable jobs in Canada, quickly go back to the country of origin to secure what they had left behind, either to pursue business or retain the high paying job that they had before leaving for Canada. Finding that the grass is greener where they are coming from, they then become shuttling or commuting husbands having one leg in Canada and the other leg outside of Canada, leaving behind their children and spouses in Canada to live and study. Usually they succeed and become permanent commuting husbands and fathers. At times however, this separation is seen as a threat to the cohesion of the family and usually encourages marital discord. The situation usually puts the female in charge of the household in Canada. Sooner than later, the minority immigrant mothers begin to experience the problem of establishing authority over their children. As these mothers try to fulfill their maternal role, their children who have a view of patriarchal family structure have difficulty in adjusting to the matriarchal role assumed by their mothers in 
their new environment and so resent the control their mothers have over them. They also reject the fact that there is no male presence in the home. So these mothers have to confront anger from their children due to the ripple effect of a situation that they did not create (Arac-Koc and Villaisin, 2001).

Frideres (2007) observes that the relationships between husbands and wives vary from culture to culture. Migration can alter the status and relations between husbands and wives and between parents and children. The immigration process inadvertently reinforces the marginalization of women and inscribes women as dependent upon their husbands. Because most women enter Canada as dependants of their husbands, this situation acts as a barrier when trying to integrate. For example, these women do not have the freedom to participate in the labor market due to their involvement in keeping their family together and ensuring that the family becomes settled. These women, on the family front, begin by being stay-at-home mums for years, minding the homes, while the men go to eke out a living. Women are the ones saddled with the responsibility of ensuring that their families settle down as quickly as possible without devastating consequences of disruptions. They explore and locate various structures needed for survival, a place to live, schools for the children, clinics and hospitals, grocery stores and shopping complexes, and transportation for easy mobility of family members. They usually place their ambition and aspirations for career pursuits on hold in order to look after their families. They also place priority on their husband's attempts to remake or restart their careers, because of the belief that when husbands have a high earning 
power, the family should be able to survive. It is only when they settle their families that women embark on their own career advancement (Frideres 2007). ${ }^{1}$

There has always been the assumption that visible minority immigrant women do not have any power because of the misconception that power usually belongs to the male. Most western researchers portray visible minority immigrant women as victims of their own culture; hence these women are seen as powerless, subdued and helpless. They suffer from a perception of weakness by the mainstream, which usually treat them as these poor women. Visible minority women fiercely detest the condescending nature of interaction with the women of the mainstream. At times, visible immigrant women develop low self esteem from this perception (Arac-Koc and Villaisin, 2001). The truth is that minority women are underestimated as active agents of authority in their homes by mainstream women. Many women from other cultures have their own centers of power and competence and at times, the men ascribe power to their women (Kimmel and Holler, 2011). There are conditions for some form of egalitarianism in many cultures. In some, power lies in the control and management of the household. Frideres (2007) observes that unknown to the mainstream; immigration to Canada provides opportunities for visible minority women to experience increased power of different dimensions in an individualistic society like Canada. If these women are able to work, participation in the labor force usually means that they go out to work, get some exposure and begin a process of integration. When they have a good job, there is a change in the power dynamics in the family. They assume a lot of responsibility, there

\footnotetext{
${ }^{1}$ Things are always more difficult for women who are professionals prior to migration; they come to Canada and find that they have to be dependent on their husbands for the first time in their lives (Frideres, 2007).
} 
Visible Minority Families

is relative autonomy, and more decision making power is exercised by them in family issues.

Marriage is considered a lifelong commitment and so divorce in some immigrant's culture is regarded as a shameful tragedy. There are times when the improved social status of visible minority immigrant women has led to conflict within the family. When women have come from a very male dominated culture, the men resent the power and the increased dominance of the women in the home which can lead to conflict and discord. The result is the prevalence of divorce of visible minority immigrants in Canada today (Creese, Dyck \& Mclaren, 2009). The light at the end of the tunnel is that although visible minority immigrant women may find living in Canada very stressful at first, they eventually tend to recreate the support that they had back home by setting up networks within their communities to help each other. Some who have experienced upward social mobility into the upper middle class and who can afford it hire domestic help to assist with the children and the household chores. This eventually grants them the freedom to explore other grounds in their integration process. (Man, 2009).

An often overlooked group, when it comes to the family dynamics of visible minority immigrants' families, is seniors. Citizenship and Immigrant Canada (CIC, 2007) indicates that many visible minority immigrants who enter Canada are preretirement age. Of course, many who enter pre-retirement age eventually become older and start to retire. Many senior citizens face economic hardship especially if they have spent most of their working lives in other countries and those countries do not provide pension benefits to aging immigrants that can be transferred to Canada. Here in Canada 
Yesufu

immigrant seniors, both permanent residents and naturalized Canadian citizens, may be eligible for Old Age Security (OAS) but are not eligible for the Canada Pension Plan (CPP) if they were not members of Canada's labour force. The fewer the years they spent in the Canadian labor force, the lower their CPP contribution and subsequently the lower their pension. To be eligible for Old Age Security, citizens or legal residents of Canada must have lived in Canada for a minimum of ten years after reaching the age of eighteen years. A person may qualify for maximum benefits if she/he has lived in Canada after reaching the age eighteen for a period of forty years (Human Resources Social Development Canada, 2007). The result is that many visible minority immigrants do not qualify for full pensions and end up living in poverty. Older visible minority immigrants usually live with family members for cultural reasons that have been mentioned before, although some of them may live on their own. Lum and Springer (2004) say that visible minority immigrant family members who have not typically used seniors and retirement homes are using them now because of the stress of looking after their aged family members while they still have to work and look after their own family. The sandwiched generations are mostly the ones who experience this stress.

Now that these visible minority immigrant families need to use these establishments, they are discovering that finding culturally appropriate centers for visible minority immigrant seniors is very difficult. Lum and Springer (2004) add that visible minority seniors who live in ethnically sensitive and appropriate residencies are less vulnerable and experience less social isolation. Culturally sensitive establishments have been found to be beneficial for visible minority seniors but there are very few of them in Canada. Some of the older visible minority immigrant communities have built 
culturally specific viable support centers for their senior population, while many of the newer visible minority groups are not affluent enough to establish such culturally competent institutions. Hence, the seniors in these communities still experience problems of settlement and adjustment as retirees in Canada (Lum and Springer, 2004).

When it comes to family abuse, visible minority immigrant families share many experiences with other families in Canada. However, immigration creates unique vulnerabilities. Visible minority immigrant families face many stressors which include underemployment and unemployment, culture shock, language barriers, limited access to resources, and economic hardship. Fridere (2007) indicates that domestic violence among immigrants follows four patterns. In the first pattern the husband takes on the instrumental role and the wife takes on the emotional role. Over time, the wife essentially becomes lonely, isolated and dependent on the husband. The husband begins to see her as a burden and this usually leads to spousal conflict. The second scenario, which is more common, is that the woman obtains new opportunities in their new immigrant situation (i.e. a job outside the home which gives her self confidence to challenge the traditional power distribution and role allocation). The husband may then experience a status change that decreases his power in the family, he then tries to maintain dominance in the relationship, with the wife resisting this, and conflict ensues. The third scenario is the conflict that arises between the generations within a family, actually in the parent/child dynamics. The general basis for this conflict is that children are growing up within a different social milieu and cultural rules from that which the parents are raised. This results in conflict because of the disconnect between the children and the parents. Fourthly, economic necessities for many visible minority 
Yesufu

immigrant families require that women and/or children enter the labour market. This tends to reverse the provider role that was previously experienced in their homeland. Visible minority immigrant women and children are able to enter the labour market more quickly because of the availability of low paying jobs for females and youth. Thus they become bread winners for the family and in turn they assume the status and power that accompanies the provider role. This inversion of roles, if not dealt with skillfully and with sensitivity, can create hostility and resentment within families. However, let it be noted that all the four scenarios may result in minor bouts of conflict but if not dealt with, may turn to serious physical and emotional abuse within families (Fridere, 2007). Husaini's (2001) study indicates that visible minority immigrant women who experience spousal abuse and intimate partner violence are less likely than nonimmigrant women to seek both formal and informal help. Cultural barriers and the pressure not to speak out for fear that disclosure to outsiders will promote criticism of their culture or ethnicity and feelings of shame, hampers these women in seeking help. These women are also less likely to seek help due to isolation, lack of language skills, fear of deportation, lack of information of available services and lack of culturally safe and culturally sensitive services available to them. Mainstream service agencies have little connection with visible minority immigrant communities and are thus ineffective in dealing with ethno-cultural community issues (Husaini, 2001).

Ali and Kilbride (2004) discuss role reversals and shifts in roles and responsibilities that occur within visible minority immigrant families. Usually children in these families attain proficiency in English or French much earlier than their parents and so they become cultural and language interpreters for their parents. This situation 
results in a dependency role reversal where parents depend on their children for support in their new environment. The differing attitudes that usually arise regarding retaining their cultural heritage and at the same time trying to establish connections with the larger society of the new country may result in conflict between the parents and their older children. ${ }^{2}$

Regarding elder abuse, Lum and Springer (2004) indicate that because it is not socially and culturally acceptable in some cultures for aged parents to be placed in longterm care facilities, most visible minority immigrants keep their aged parents at home. Ambert (2012) says that providing care for the elderly causes psychological, emotional and economic burdens for families, thus increasing the risk of elder abuse. She adds that elder abuse has low visibility among visible minority immigrant families as it is not often mentioned because of the embarrassment that may be felt by the families in the communities. Elderly parents too, may be ashamed of their situation and so may not turn to anyone for help. Overall, family violence in all families both visible and nonvisible seems to increase when such factors such as economic deprivation, alcoholism, and substance abuse are evident in the family. However, the visible minority immigrant population still enjoys support from their communities in addressing the cases of most forms of family violence, spousal, parent and child abuse (Kurst-Swanger and Petcosky, 2003).

\footnotetext{
${ }^{2}$ Husaini (2001) adds that shifts and reversals in the roles of husband and wife relationships may also occur especially when the wife finds a low paying but full-time employment before the husband. This results in her assuming some responsibilities in the home which may lead the husband to feel the erosion of some of his power. This may cause some tension and conflict between them.
} 
Yesufu

\section{Overall View of the Challenges of Visible Minority Families}

Talibani and Hasanali (2000) state that often people speak of visible minority immigrant families as if they are a homogenous group. The truth is that there is a great deal of diversity amongst them, even though they share some common characteristics and experiences. Visible minority immigrant families differ in their reasons for coming to Canada, in how they are received, in their levels of adjustment, the pattern of family structure they eventually settle into, and the contributions that they make to their new land. The experiences of visible minority immigrant families in time differ from one family to the other. Some families have high levels of educational achievement with secure jobs, some do not. For some, immigration is a process rather than a single event. It involves not only leaving a home land and crossing territorial borders but also continuously crossing social, psychological and symbolic borders which define identity relations, membership, belongingness, meanings, systems and world view of the realities of everyday life.

Talibani and Hasanali (2000) add that the experiences of all immigrants including visible minority groups reveal a fundamental uniformity. They have been uprooted from their old surroundings. Their overall story has been their willingness to look beyond the horizon and in their readiness to seek a new life. Despite the various levels of difficulties that they experience, they persevere, they seek education, they work hard and eventually some of them "make it". Hiller (2005) says that Canada's current immigration policies are designed to unite families, to foster strong and viable economic independence in all regions of the country and to fulfill Canada's legal obligations and compassionate and humanitarian traditions of respecting immigrants 
and refugees. Today, it can be said that Canada no doubt owes some of its development to the various immigrants that have come and have contributed to it. Immigrants for over one hundred years have increased Canada's population. They have diversified the ethnic composition of the country to the admiration of many other countries that are trying to emulate Canada's immigration policy (Hiller, 2005). Immigrants have contributed to both the agrarian economy of old and the current industrial and servicebased economy of Canada. Immigrants come with lots of skills and experiences which have been ignored in the past. Canada is making efforts to rectify this problem with the various Bridges and Integration programs for professionals to resolve the experience problem which has hindered many immigrants from integrating (Mennonite Centre for New Comers, 2010).

Despite these programs, Reitz (2007) observes that race still matters in Canada. It is a fundamental source of meaning and recognition. He adds that it is easy to suggest that race is insignificant if one is not a member of a racialized minority. Race and ethnicity affect peoples' lives; they affect how people are treated and how they live. They provide power and privilege for some. They often form the basis of hierarchical rankings that determines who gets what resources. Visible minority immigrant families in Canada continue to have challenges and problems in terms of access to resources and opportunities. Negative experiences of visible minority immigrant families have resulted in the deterioration of their social status and a downturn in their economic situations and at times, these problems have not improved as quickly as the immigrants would like, although some have reported much improved household income levels after some time (Reitz, 2007). Immigrants both visible and non-visible usually classify 
Yesufu

themselves as first, second, third or subsequent generations of immigrants. The notion that with each generation of immigrants the differences between the descendants of immigrants and Canadian children become indistinguishable has been debunked. Reitz (2007) says that the experiences of visible minority immigrants sometimes remain negative despite years of living in Canada.

As had been documented, cultural patterns and attitudes towards family structure, parenting practices, gender dynamics, the aging process, and domestic violence, all influence the experiences of visible minority immigrant families in Canada. They continue to experience systemic barriers and their children, who have witnessed discrimination against their parents, have become averse to it or resentful. These young visible minority groups will always possess the same physical characteristics that will continue to separate them from the rest of the society (Clark, 2007). Canada will continue to be a land of immigrants. Canada's racial and ethnic diversity will continue to increase because of immigration. While Canadians celebrate the value of diversity, there are still challenges that visible minorities face in this multicultural society. As the diversity in Canada increases there is the possibility that inter-ethnic tensions may increase. Canada needs to promote some measures that will reverse or reduce the incidents of racism and discrimination against visible minority groups to ensure a healthy development and integration of the younger generation in the land that they call home (Clark, 2007).

Like all families in Canada visible minority immigrant families are shaped by government policies and the broader social and economic realities that surround them (Albaneze, 2009). Baker (2009) explains that social and economic policies impact on 
Visible Minority Families

family life. Hence, the state needs to protect vulnerable families. Government may have tried to strengthen families in general but with regard to visible minority immigrant families, there needs to be a deliberate concerted effort to address some of the severe problems. A Statistics Canada study prepared for Canadian Heritage, Human Resources and Skills Development Canada and Citizenship and Immigration Canada released in 2010, predicted that visible minorities in Canada will double by 2031. If left unaddressed, the challenges faced by visible minority immigrants may become greater and more difficult to address in the future. To reduce the impact of these challenges the government's perspective is that multiculturalism policy should be expanded to embrace a more socially active commitment to developing positive relations between groups while Canadian immigration priorities and policies need to be reevaluated to ensure smoother integration of the families into Canadian society.

\section{Cultural Sensitivity to the Rescue}

At the individual level, which this writer is more concerned with, there needs to be the development of cultural sensitivity. Most people would agree that education is transformative. Hence, various educational programs, Global Education, Multicultural Education, Intercultural Education, Antiracist Education, and Diversity Education have all been put in place in Canada to help address the problems that continue to be visible in the interaction between the majority and the minority population of Canada despite the increase in diversity. Unfortunately, all of the programs that have been put in place have been shown to have some pitfalls. Some of them have been criticized even by their supporters. For example, Muller (2001) says Global education has become multipurpose; a one word catch-all phrase that refers to all programs offered by all and 
Yesufu

any faculties, departments, colleges, universities schools programs who think that global education gives credibility to their programs in terms of global perspectives. Global education has also become driven by various agendas. Special interest groups largely outside the classroom like the United Nations and other International Agencies, World Bank, Foundations, the Business sector, Church agencies, and Non-governmental agencies have all been jumping on the band wagon of Global Education and defining its content and purpose. Global education has not served any practical purpose in the Canadian situation as seen since its inception.

Multicultural Education was designed to advance the goals of Canada's Official Multiculturalism Policy. Unfortunately, its focuses excessively and is preoccupied with the exotic aspects of culture; the emphasis on cultural events, religious holidays, dress, dance, and food. This education ignores the effects of racism and discrimination on the victims. It also fails to confront minority grievances and aspirations. It does not seek to redress the inequities between minorities and the majority. Multicultural education has been criticized since the early days of its formation. Nieto (1994) says it ignores the institutional basis of domination and discrimination. MacAndrews (1991) one of its earliest critics cited Hari Lalle Curriculum consultant for Antiracist education at the Toronto Board of Education who says, that Multicultural education gives one the illusion that one is doing a lot of work, but it creates a non-action and a sort of passive tolerant mode. Everyone feels tolerant but they don't practice tolerance.

Antiracist Education as pedagogy recognises racism, sexism, and classicism as the by-product of dominant societies and seeks an equitable resolution to a skewed power structure. But Antiracist education is considered radical and so it invokes 
resentment. Raising the issue of racism causes problem, hence it has become a counterproductive program that is rarely taught anymore. Carr and Klassen (2008) depose that Antiracist education is designed to address the inequities and systemic barriers in educational institutions, to provide a voice to all groups and individuals, from marginalized backgrounds and to legitimize and validate their lived experiences. They however observed that its implementation have been hampered by some structural institutional barriers which have continued to reinforce and perpetuate inequitable power relations, alienate and marginalize some groups, and have a deleterious effect on all participants.

Intercultural Education has the study of culture at its heart and has a strong intercultural communication focus. The problem with this program has always been which language needs to be learned. For the immigrant, skill or proficiency is determined by the ability to speak the host's language. This is deemed as a hidden agenda by some for domination by the dominant culture. It may indirectly promote ethnocentrism, which suggests that Western standards are right because it is dominant. ${ }^{3}$.

Diversity education focuses on all forms of differences in the systems. It ensures that these differences are valued and appreciated. Unfortunately, diversity education which excessively focuses on differences and less on similarities, has become an add and stir effort with limited content on culture which is needed for cross-cultural awareness and cross-cultural competence. Diversity, of course, has become a buzzword by organizations and corporations to address organizational effectiveness and conducive workplace environment. It is also used to address staff diversity in organizations. It is

\footnotetext{
${ }^{3}$ UNESCO (1998) defines intercultural education as education for peace and human rights. I am not sure this resonates with the bigots on the streets.
} 
Yesufu

also seen as a form of affirmative action which should satisfy the minority population.

The sprinkling and token measure of minority members of staff is being touted as diversity in the workplace and is assumed to promote cultural unity and understanding. Technically these five forms of cross-cultural educational programs are meant to serve as educational reforms to enhance understanding between people and between cultures. Unfortunately, the tensions between cultures remain and the challenges of the visible minority immigrants have persisted (Yesufu, 2006).

Stafford, Bowman, Eking, Hannah and Lopes DeFede (1997) define cultural sensitivity as being aware that cultural similarities and differences do exist and have an effect on values, learning and behavior. Many Canadians are aware of the apparent diversity in the Canadian society. Some have accepted that diversity, some have come to terms with it, but not many have come to understand the full implication of that diversity. Discrimination and racism, both subtle and overt, continue to be experienced by visible minorities everywhere, in the streets, in the workplace, in schools, even in religious institutions which are supposed to be more welcoming. Cultural sensitivity is not to be confused with cross-cultural competence and intercultural communication which are also promoted in the diversified societies. Cultural sensitivity is a lot more than the study of culture which Aoki (1996) thinks is a political struggle. The problem is that each of the aforementioned educational programs is not sufficient on its own. They all mean well and have lofty goals, but as indicated, they all have some deep rooted and inherent deficiencies.

What is therefore needed from this writer's perspective is the emergence of a new program that will integrate all of what is currently available with a new program 
that will affirm that the cultural system of a society is based on a coherent set of values that make sense to the members of that society; a new program that will emphasize that there are strengths in each culture and that cultures of other lands are not simply exotic, but worth absorbing. In the case of Canada, some of these new immigrants are either trying to flee unstable political conditions or are trying to improve their economic prospects. Fleeing their native land does not mean they are less than human or that they are rejecting their cultural heritage. This new program will seek to preserve the individual's cultural identity and resist the homogenization of all cultures as proposed by some form of global education.

This new program will not fall into the tolerance mode, the greatest deficiency of multicultural education. Williams-Shreeve (1991) says that the concept of tolerance makes people of diverse cultural backgrounds live side by side, yet not together. Kach Nick \& Ki Su Kim (1991) state that tolerance brings with it disturbing connotations and has been suspected of being the cause of the social disharmony that can be heard echoing throughout Canada's many diverse cultures. Vertovec (1997) declares that tolerance has been defined as begrudging acceptance. He adds that it is a vague and overused concept, which if not carefully defined, might provide opportunity for marginalization and discrimination. Thomas Paine (1792) in the Rights of Man said that tolerance is not the opposite of intolerance, but is the counterfeit of it, and that both are despotisms. DeFaveri (1995) says that tolerance is indifference, which means not to care one way or the other. Stebbins (1998) says that there is something smug about tolerance. It asserts one's superiority despite its best intentions. He added that there is perhaps an element of pity and condescension. Nieto (1994) describes tolerance as a superficial 
Yesufu

band-aid or a feel good additive, adding that it is the acceptance of the status quo and slight accommodation to difference. To tolerate means to endure; not embrace. Nieto identifies tolerance as the lowest level of supporting diversity, the next level up is acceptance and she rates respect as the highest.

This new program will also avoid the radicalism of antiracist education. It will display more solidarity than the current intercultural education. It will not promote the other diversities to the disadvantage of cultural diversity, as does diversity education now. Cultural sensitivity is the quality of accepting people as people. This new program will first and foremost present all people as people. This new program will embrace the Culture of Peace concept promoted by UNESCO (1998) which says "The culture of peace is based on the principles established in the Charter of the United Nations and on respect for human rights, democracy and tolerance ....... (A/Res/52/13, 15 January 1998, para. 2). Cultural sensitivity is not achieved with diversity in staff composition. It is more than courses to be taught formally at primary, secondary or tertiary levels of education. Cultural sensitivity is an attitude. It is developed. It has a continuum. A culturally sensitive person is aware that there could be differences between their culture and another person's, and that these differences could affect their relationship and the way they communicate with each other. A culturally sensitive person would understand other people's traditions and ways of life, and would attempt to learn and apply new understandings. Most importantly, culturally sensitive people would make efforts to be free from prejudices and preconceptions about other people and not to simply glaze over them with polite racism. It behooves each individual to take a conscious decision to change and it requires all to bear some responsibility for a turn-around in attitude. 
Visible Minority Families

People must continue to oppose discrimination and racism in everyday life, adopt and encourage a change in attitude for Canada to become a truly integrated society.

Cultural sensitivity implies that everyone accepts the efforts that will be aimed at healing divisions among racial groups. Children must be taught about cultural sensitivity to ensure a safe society. Canada's commitments to equality and diversity need to be reinvigorated in order to truly foster a meaningful and lasting sense of belonging for men, women and children immigrants to Canada now and in the future. There is also a need to explore various ways of bringing groups together for more authentic and successful interaction. Canada needs to ensure that inequality is diminished so as to reduce the threat of insecurity in the society. Those elements that pose substantial threats to social cohesion and overall well being of the heterogeneous population of Canada must be stopped. Hence, cultural sensitivity needs to be promoted at all non-formal educational settings.

Patriquin (2007) in MACLEANS, one of Canada's foremost magazines in its October $22^{\text {nd }} 2007$ edition published a Report on an investigative research on Canada: A Nation of Bigots? Surprisingly, the article says that Canada thinks of itself as beacon of tolerance but the evidence suggests otherwise. The article documents various experiences and expressions of discrimination, prejudice and racism in Canada. It was a bold attempt by the magazine to deliver the most poignant view of racism in Canada. Cultural sensitivity is needed in the community, in schools, in churches, in mosques, in temples, in synagogues, in the workplace, in organizations, in all places. It is like the Good News that must be taken to the highways and the byways. The propagation of which will result in an astounding ripple effect. Cultural sensitivity has the ability to 
transform the Canadian society in to a more dynamic and overall sensitive one. A more

specific way of integrating and infusing cultural sensitivity as a non-formal program

into every aspect of Canadian life will be discussed in a subsequent article.

\section{References}

Abella, R.S. (1984). Equality in Employment: A Royal Commission Report. Minister of Supply and Services. Ottawa.

Albaneze, Patrizia (2007). Introduction to Canada's Families: Variations in Definitions and Theories. In David Cheal (ed) Canadian Families Today: New Perspectives. Oxford University Press. Ontario.

Albanese, Patrizia. (2009). Ethnicity, Immigration and Family Life. In Maureen Baker (ed.) Families: Changing Trends in Canada. (pp.130-153) McGraw Hill Ryerson. Toronto.

Aoki, Doug The Thing of Culture, In University of Toronto Quarterly Review, Vol. 65, Spring 1996.

Alboim, Naomi and Cohl, Karen, (2112) "Shaping the future: Canada's rapidly changing immigration policies," The Maytree Foundation Report on the rapidly changing immigration policies and refugee systems by the Conservative government between 2008 and 2012. Retrieved from http://maytree.com/wpcontent/uploads/2012/10/shaping-the-future.pdf

Dobrowolsky, Alexandra (2010) Immigrant Women, Equality and Diversity in Canada. Equity Matters: Royal Commission on the Status of Women. Toronto.

Ali ,M and Kilbride, K (2004) Forging New Ties Improving Parenting And Family Support Services For New Canadians With Young Children. Human Resources and Skill Development Canada. Ottawa.

Ambert, Anne Marie (2012) Changing Families: Relationships in Context. Pearson Toronto.

Arat-Koc, Sedef, (2009). The Politics of Family and Immigration in the Subordination of Domestic Workers in Canada. In Bonnie Fox (ed) Family Patterns: Gender Relations pp 428-452. Oxford University Press. Ontario

Arat-Koc, S and Villaisin, M (2001). Caregivers break the silence: A participatory Action Research on the Abuse and Violence including Impact of Family Separation Experienced by Women in the Live in Caregiver Program. Toronto

Bakan, Abigail and Daiva, Stasiulis (1994), Foreign Domestic Worker Policy in Canada and the Social Boundaries of Modern Citizenship. In Science \& Society, Vol. 58, No. 1 Spring, pp. 7-33 Published by: Guilford Press

Beiser at all (2002). Poverty, Family Process and the Mental Health of Immigrant Children in Canada. In American Journal of Public health vol. 92 (2) pp. 220229

Boyd, M and Vickers, M ( 2004). The Ebb and Flow of Immigration in Canada. In J Curtis, E, Grabb, N. Gruppy, (eds), Social Inequality in Canada: Patterns Problems, and Policies pp258-284 .Pearson Prentis Hall. Toronto 
Visible Minority Families

Brandon, P. (2004). The Childcare Arrangements of Pre age School Children in Immigrant families in the United States. In International Migration 42, 1: pp 6588.

Brenizer, Susan Hartman (2010) Shrink Rap: Have you 'Parentified' your child? Article in Syracuse.com

Canadian Social Development Council (2000) and Canada, Treasury Board Secretariat (2000), on the Federal Public Service.

Carr, Paul and Klassen, Thomas (2008) Institutional Barriers to the Implementation of Antiracist Education: A Case Study of the Secondary System in a Large, Urban School Board

Christensen, Carol Pigler. (2001). Immigrant Minorities in Canada. In Joan Turner and Francis Turner (eds).Canadian Social Welfare (pp.180-209). Pearson. Allyn and Bacon. Toronto.

CIC (2009). Canada Immigration news letter

Clark, Warren (2007). Delayed Transitions of Young Adults .In Canadian Social Trends 84 13-21.

Creese, G, Dyck, I, McLaren, A. (2009) Gender Generation and the Immigrant Family Negotiating Migration Processes. In Bonnie Fox (ed) Family Patterns: Gender Relations pp 496-506. Oxford University Press. Ontario.

DeFaveri, Education and the Limits of Tolerance, In Essays on Canadian Education. Spring1995.

Doucet, Andrea (2007). Families and Work. In David Cheal (ed) Canadian Families Today: New Perspectives (pp.136-153). Oxford University Press. Ontario.

Edmonton Mennonite Centre for Newcomers Programs publication (2010)

Fleras, Augie. (2005). Social Problems in Canada: Conditions, Constructions and Challenges. Pearson Prentice Hall. Toronto.

Frideres, J.S. (2007). Building Bridges: Aboriginal, Immigrant and Visible Minority Families in the Twentieth Century. In David Cheal (ed) Canadian Families Today: New Perspectives (pp.195-212).Oxford University Press. Ontario.

Henry ,Frances (2004).Two Racial studies of Racial discrimination in Employment. In Curtis, J, Grabb, E and Guppy, N (eds) Social Inequality in Canada: Patterns Problems and Policies (pp285-294).Pearson Prentice Hall. Toronto.

Hiller, Harry (2005). Canadian Society: A Macro Analysis. Pearson, Toronto.

Hou, Feng and Balakrishnan, T (2004). The Economic Integration of Visible minorities in Contemporary Canadian Society. In Curtis, J, Grabb, E and Guppy, N (eds) Social Inequality in Canada: Patterns, Problems and Policies (pp273-284). Pearson Prentice Hall Toronto.

Husaini, Z. (2001) Cultural Dilemma of Canadian Ethnic Women. Intercultural Action Committee for the Advancement of Women, Edmonton.

Hutter, Mark. (2004). Immigrant Families in the City. In Mark Hunter (ed) The Family Experience; a Reader in Cultural Diversity (pp 22-29) Pearson, Allyn and Bacon Toronto.

James (2011) Welcoming 'Visible Minorities': Paradoxes of Equity hiring in Canadian Universities In Equity Matters. Canadian Federation for the Humanities and Social Sciences. Fedcan Blog. 
Yesufu

Jedwab, Jack (2004) Diversity of Marriage: Canadian Opinion on Cross Cultural Marriage. Canadian studies Toronto

Jha ,M. (2001). In defense of the he Joint Family system .In A Social Study of the Benefits of the Joint Family System.

Jones, Maldwyn Allen (1960) American Immigration . Chicago University of Chicago Press.

Kach, Nick, \& Ki Su, Kim, Multiculturalism and Multicultural Education in Canada: Problems and Promise, In Multicultural Societies, New York 1991

Kimmel, M and Holler J (2011) The Gendered Society .Oxford University Press. Ontario.

Kobayashi, Audrey. (2010). Equity and Women of Color. In Equity Matters. Canadian Federation for the Humanities and Social Sciences. FedCan Blog.

Kurst-Swanger ,Karel and Petcosky, Jacquline (2003). Violence in the Home : Multidisciplinary Perspectives. Oxford University Press. Toronto.

Lum, J and Springer S (2004) The Ageing Experience Of Chinese And Caribbean Seniors. In Policy matters pp8 1-7

McAndrews, Marie (1991) Ethnicity, Multiculturalism and Multicultural Education in Canada. In Social Change and Education in Canada, Toronto: Harcourt, 1991.

Man, Guida (2009). From Hong Kong To Canada . In Bonnie Fox (ed) Family Patterns Gender Relations pp 496-506. Oxford University Press Ontario

Muller, Robert (2001) Global Citizenship, In Education for Global Citizenship, Oregon: Global Education Associates 2001.

Nieto, Sonia Moving Beyond Tolerance in Multicultural Education. In Multicultural Education, Spring 1994

Olson, D, DeFrain, J, Skogrand, L (2008) Marriage and Families: Intimacy, Diversity and Strengths. MacGraw Hill Toronto .

Paine, Thomas (1792) The Rights of Man. For the Use and Benefits of All Mankind. Printed and sold By Citizen Daniel Isaac Eaton. Printer and Bookseller to the Supreme Majesty of the People at the Cock and Swine at No 74 Newgate Street. London.

Patriquin, Martin (2007) Canada: A Nation of Bigots? Investigative Report in MACLEANS October 222007 Edition pp 16-22

Reitz, Jeffrey. (2007) Immigrant Employment Success in Canada, Part I: Individual and Contextual Causes. Article prepared with the financial support of Human Resources and Social Development Canada, Ottawa. Published online: 31 October 2007.

Rer-Stier, D. (1996) Coping Strategies of Immigrants Parents: directions for family therapy. Family Processes vol35 pp363-376

Satzewich, Vic (2000) Social Stratification: Class and Racial Inequality. In Singh Bolaria (ed) Social Issues and Contradictions in Canadian Society (pp165-194). Harcourt Brace. Toronto.

Sesdef, Arac-Koc (2009) The Politics of Family and Immigration in the Subordination of Domestic Workers in Canada. In Bonnie Fox (ed) Family Patterns Gender Relations pp 496-506. Oxford University Press Ontario

Simms, Glenda (1990). Coming To Terms with "Visible Minority" Canadian Congress for Learning Opportunities for Women (CCLOW) March 1990 - Vol. 7, No. 4 
Smith, Malinda (2011 January 5) Leading on Equity and Diversity Matters: Yes We Can, and Yes We Will! In Equity Matters. Canadian Federation for the Humanities and Social Sciences. FEDCAN Blog. Retrieved from . http://starsusask.blogspot.ca/2011/09/fedcan-blog-entries-of-interest.html

Statistics Canada( 2005), Ethnic Diversity Landmark Survey.

Statistics Canada (2008). 2006 CENSUS Report Toronto

Stebbins, Robert Tolerance: Pluralism and Conflict, Scarborough: McGraw Hill Ryerson 1988.

Talibani, J and Hasanali, P (2000).Gender Role Socialization in South Asian Immigrant Culture. In Journal of Adolescence 23(5) 615-6270 88 108, 1113.

Ujimoto, Victor (2000). Multiculturalism, Ethnic Identity and Inequality. In B. Singh Bolaria (ed) Social Issues and Contradictions in Canadian Society. (pp.228246). Harcourt Brace. Toronto.

UNESCO (1998) Proclamation of the Year 2000 as the International Year of the Culture of Peace. (A/Res/52/13, 15 January 1998, para. 2)

Vertovec, Steven. Social Cohesion and Tolerance, A discussion Paper, Metropolis Conference, Copenhagen, 1997.

Williams-Shreeve, Tracy Multicultural Education vs. Antiracist Education, Unpublished article, 1991

Yesufu, A. O. (2006). "Global Education, Multicultural Education, Intercultural Education Antiracist Education, Diversity Education, Are they all roads leading to the same destination?" International Journal of Diversity in Organizations, Communities and Nations, 4, 1133-1138 